\title{
Bio-Cementation for Improving Soil Thermal Conductivity
}

\author{
Liang Cheng ${ }^{1}$, Natalia Afur ${ }^{2}$ and Mohamed A Shahin ${ }^{2, * \mathbb{D}}$ \\ 1 School of Environmental and Safety Engineering, Jiangsu University, Zhenjiang 212013, China; \\ clcheng@ujs.edu.cn \\ 2 School of Civil and Mechanical Engineering, Curtin University, Bentley, WA 6102, Australia; \\ natalia.afur@student.curtin.edu.au \\ * Correspondence: m.shahin@curtin.edu.au
}

Citation: Cheng, L.; Afur, N.; Shahin M.A. Bio-Cementation for Improving Soil Thermal Conductivity. Sustainability 2021, 13, 10238. https:// doi.org/10.3390/su131810238

Academic Editor: Syed Minhaj Saleem Kazmi

Received: 3 August 2021

Accepted: 9 September 2021

Published: 14 September 2021

Publisher's Note: MDPI stays neutral with regard to jurisdictional claims in published maps and institutional affiliations.

Copyright: (c) 2021 by the authors. Licensee MDPI, Basel, Switzerland. This article is an open access article distributed under the terms and conditions of the Creative Commons Attribution (CC BY) license (https:/ / creativecommons.org/licenses/by/ $4.0 /)$.

\begin{abstract}
A promising technology for renewable energy is energy piles used to heat and cool buildings. In this research, the effects of bio-cementation via microbially induced calcite precipitation (MICP) using mixed calcium and magnesium sources and the addition of fibres on the thermal conductivity of soil were investigated. Firstly, silica sand specimens were treated with cementation solutions containing different ratios of calcium chloride and magnesium chloride to achieve maximum thermal conductivity improvement. Three treatment cycles were provided, and the corresponding thermal conductivity was measured after each cycle. It was found that using $100 \%$ calcium chloride resulted in the highest thermal conductivity. This cementation solution was then used to treat biocemented soil samples containing fibres, including polyethylene, steel and glass fibres. The fibre contents used included $0.5 \%, 1.0 \%$ and $1.5 \%$ of the dry sand mass. The results show that the glass fibre samples yielded the highest thermal conductivity after three treatment cycles, and SEM imaging was used to support the findings. This research suggests that using MICP as a soil improvement technique can also improve the thermal conductivity of soil surrounding energy piles, which has high potential to effectively improve the efficiency of energy piles.
\end{abstract}

Keywords: bio-cementation; microbially induced calcite precipitation; thermal conductivity; energy piles

\section{Introduction}

Most energy production on a global scale comes from fossil fuels. This reliance on fossil fuels has led to some drastic environmental repercussions on a global scale through the effects of climate change. From the melting of polar ice caps, rising sea levels and bleaching of formerly vibrant coral reefs, to the diminished productivity of agriculture and the destabilisation of local ecosystems, the consequences of climate change are indisputable [1]. To safeguard the future, there is an ever-increasing need to prioritise energy production through renewable technology.

One source of renewable energy is the earth-stored thermal energy, also known as geothermal energy. One of the most common, direct uses of geothermal energy is energy piles, which can regulate the temperature within buildings by transferring thermal energy through a medium [2]. The main path of heat transfer occurs where the soil particles are in contact; larger contact surfaces play a significant role in improving the soil thermal conductivity.

An emerging method for improving soil properties in geotechnical engineering has been developed by incorporating biological processes. Microbial-induced calcite precipitation (MICP) is one such biological technique that is gaining popularity due to its sustainable and effective approach to soil improvement [3-5]. This method stems from the hydrolysis of urea, which is facilitated by the urease enzymes produced by bacteria. The hydrolysis of urea decomposes into ammonium ions $\left(\mathrm{NH}_{4}^{+}\right)$and carbonate ions $\left(\mathrm{CO}_{3}^{2-}\right)$ in the presence of water, as shown in Equation (1) [6]. The carbonate ions react with the calcium ions to 
produce calcium carbonate (calcite), which acts as a binding agent for the soil, as displayed in Equation (2).

$$
\begin{gathered}
\mathrm{CO}\left(\mathrm{NH}_{2}\right)_{2}+2 \mathrm{H}_{2} \mathrm{O} \rightarrow 2 \mathrm{NH}_{4}^{+}+\mathrm{CO}_{3}^{2-} \\
\mathrm{Ca}^{2+}+\mathrm{CO}_{3}^{2-} \rightarrow \mathrm{CaCO}_{3}
\end{gathered}
$$

The calcite crystals formed by the MICP do not only enhance the mechanical properties of soil but were also found to improve soil thermal conductivity by $25 \%$ [7]. This is attributed to the produced precipitates of calcite crystals, which increase the contact area of soil grains, providing a path for heat transfer and resulting in higher soil thermal conductivity [8,9]. Although in most studies the calcium was the only cation source for $\mathrm{MICP}$, the advantages of substituting calcium with magnesium were recently disclosed. It has been reported that the addition of $\mathrm{MgCl}_{2}$ would increase the precipitation ratio of carbonate crystals, modify the crystal polymorph promoting more aragonite precipitation, and contribute to higher UCS, compared with the bio-cemented sample without any magnesium ions $[10,11]$. However, the effect of such MICP using mixed calcium and magnesium sources on thermal conductivity has not been studied yet.

Fibres are often used to improve the ductile behaviour of soil stabilisation [12-14]. In bio-cementation, it was found that the inclusion of carbon fibre could increase the production of calcite crystals by $14.3 \%$ due to the facility of the bacteria culture to adhere to the fibres [15]. However, a high content of fibre (greater than 1\%) would reduce the compressive strength, which was attributed to the calcite crystals precipitating around the carbon fibres rather than the sand particles, thus reducing the bonds between the soil grains. Although the mechanical properties of fibre-MICP-treated soil have been investigated in the literature, the thermal conductivity of such soil has not yet been reported.

This research is motivated by the increasing demand for renewable energy technologies to develop environmental sustainability by reducing greenhouse gas emissions. The purpose of this study is thus to determine how the thermal conductivity of MICP-treated sand can be optimised to aid the efficiency of geothermal energy piles. In addition, this work aims to investigate whether the inclusion of different fibres assists in improving soil thermal conductivity.

\section{Materials and Methods}

\subsection{Soil}

Silica sand was used for this study and the sieve analysis was performed following the AS 1289.3.6.1 to determine the particle-size distribution of the used sand [16]. The Unified Soil Classification System (USCS) classified the sand as poorly graded sand (SP) with a uniform particle size of $0.425 \mu \mathrm{m}$. The particle-size distribution is displayed in Figure 1, and the properties of sand are outlined in Table 1.

\subsection{Ureolytic Bacteria and Cementation Solution}

Bacillus sp. bacteria isolated from previous work were used in the current study [17]. The bacterial growth medium was prepared using $20 \mathrm{~g} / \mathrm{L}$ yeast extract, $18 \mathrm{~g} / \mathrm{L}$ ammonium chloride and $0.1 \mathrm{mM}$ nickel chloride with a final $\mathrm{pH}$ value adjusted to 9.25 . The pure bacterial strain was inoculated and cultivated in the growth medium under sterile aerobic batch conditions at a constant temperature of $30^{\circ} \mathrm{C}$. After $48-72 \mathrm{~h}$ of cultivation, the cultivated culture with an optical density $\left(\mathrm{OD}_{600}\right)$ of $1.5-2.0$ and urease activity of approximately $13 \pm 1 \mathrm{U} / \mathrm{mL}$ was harvested and then stored at $4{ }^{\circ} \mathrm{C}$ before use [18]. Equal molar concentrations of urea and calcium chloride or magnesium chloride were adopted for the preparation of the cementation solution. Several groups (A-F) of soil samples were prepared with varying contents of calcium chloride and magnesium chloride. Table 2 shows the concentration of urea, calcium chloride and magnesium chloride tested in this study. 


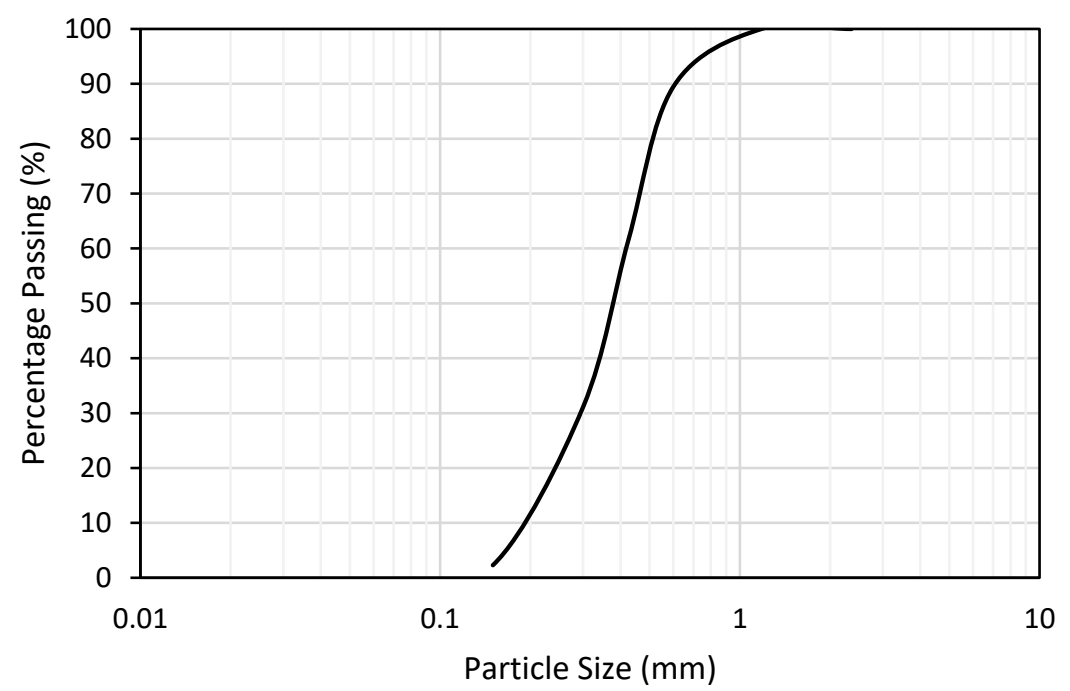

Figure 1. Particle-size distribution of silica sand used.

Table 1. Properties of silica sand used.

\begin{tabular}{cc}
\hline Property & Value \\
\hline $\mathrm{D}_{10}(\mathrm{~mm})$ & 0.17 \\
$\mathrm{D}_{30}(\mathrm{~mm})$ & 0.19 \\
$\mathrm{D}_{60}(\mathrm{~mm})$ & 0.40 \\
$\mathrm{C}_{\mathrm{u}}$ & 2.35 \\
$\mathrm{C}_{\mathrm{c}}$ & 0.53 \\
$\mathrm{G}_{\mathrm{s}}$ & 2.71 \\
$\mathrm{e}_{\min }$ & 0.48 \\
$\mathrm{e}_{\max }$ & 0.71 \\
$\eta(\%)$ & 40 \\
$\mathrm{k}\left(\times 10^{-5} \mathrm{~m} / \mathrm{s}\right)$ & $80 \pm 0.5$ \\
USCS Classification & $\mathrm{SP}$ \\
\hline
\end{tabular}

Table 2. Composition of cementation solution.

\begin{tabular}{cccccc}
\hline Group & $\% \mathbf{C a C l}_{\mathbf{2}}$ & $\mathbf{\%} \mathbf{M g C l}_{\mathbf{2}}$ & $\mathbf{C a C l}_{\mathbf{2}} \mathbf{( M )}$ & $\mathbf{M g C l}_{\mathbf{2}} \mathbf{( M )}$ & Urea (M) \\
\hline $\mathrm{A}$ & 100 & 0 & 1 & 0 & \\
$\mathrm{~B}$ & 80 & 20 & 0.8 & 0.2 & \\
$\mathrm{C}$ & 60 & 40 & 0.6 & 0.4 & 1 \\
$\mathrm{D}$ & 40 & 60 & 0.4 & 0.6 & \\
$\mathrm{E}$ & 20 & 80 & 0.2 & 0.8 & \\
$\mathrm{~F}$ & 0 & 100 & 0 & 1 & \\
\hline
\end{tabular}

\subsection{Fibre Used}

Three types of fibres were used in this study, including glass fibre, steel fibre and polyethylene fibre. The properties of each type of fibre are outlined in Table 3.

Table 3. Properties of fibres.

\begin{tabular}{cccc}
\hline Fibre Properties & Glass Fibre & Steel Fibre & Polyethylene Fibre \\
\hline Density $\left(\mathrm{g} / \mathrm{cm}^{3}\right)$ & 2.7 & 7.8 & 0.92 \\
Young's Modulus $(\mathrm{GPa})$ & 80 & 215 & 12 \\
Tensile Strength $(\mathrm{MPa})$ & 2480 & 1600 & 600 \\
\hline
\end{tabular}




\subsection{Sample Preparation and Treatment Procedure}

A split mould was fabricated for this study using cylindrical PVC of $55.0 \mathrm{~mm}$ internal diameter (as per AS/NZS 1477:2017 Table 4.1) [19] and $110 \mathrm{~mm}$ height. Water was added to the silica sand to reach an optimum moisture content (OMC) of $15 \%$. The sand was then scooped into the mould in 3 equal layers. Each layer was tamped with a steel rod 25 times to ensure that all samples had uniform densities. The top of the sample was then levelled and sealed with the pipe fitting, ready for the MICP treatment.

The MICP treatment outlined previously was implemented in this study $[20,21]$ and is shown in Figure 2. The sand specimens were firstly saturated for $24 \mathrm{~h}$ with tap water, then a half void volume of the bacteria culture was injected into the samples with a downward flow and an injection rate of $5 \mathrm{~mL} / \mathrm{min}$, and a retention period of $1 \mathrm{~h}$ was provided to allow the bacteria to uniformly distribute and adhere to the sand particles. After this period, a half void volume of cementation solution was injected at the same rate (1st treatment). After 24-h curing, a full void volume of cementation solution was injected (2nd treatment), and the sample was left to cure for another $24 \mathrm{~h}$ and then injected once more with a full void volume of the cementation solution (3rd treatment). Overall, a maximum of three treatment cycles was applied to all sand samples.

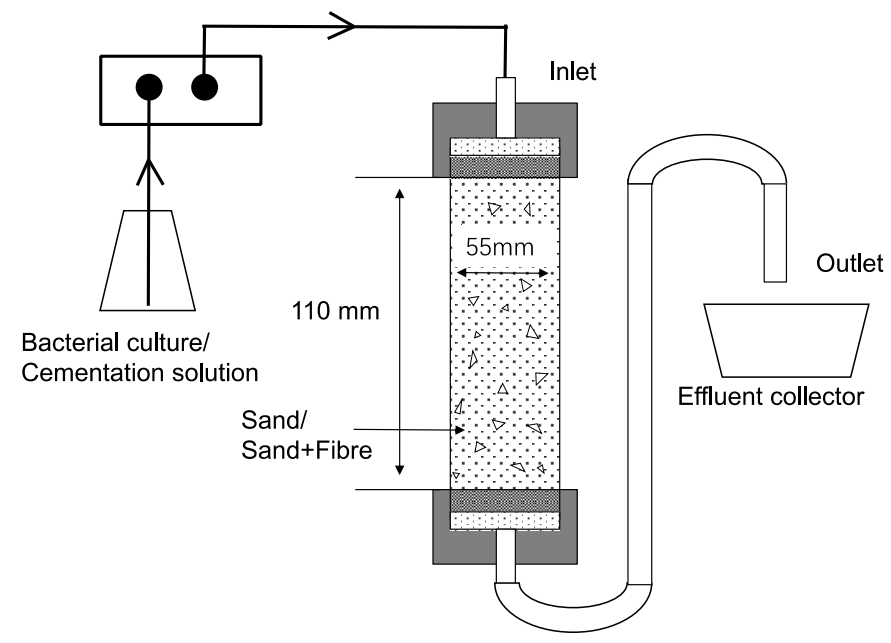

Figure 2. Schematic diagram of sample treatment.

For the fibre-soil experiment, the fibres were mixed with the sand before scooping the sand into the mould, as mentioned above. The quantities of fibre used in this study included $0.5 \%, 1 \%$ and $1.5 \%$ as a percentage of dry sand weight. The soil samples with varying fibre contents were prepared and treated with cementation solution containing $1 \mathrm{M} \mathrm{CaCl}_{2}$, following the same procedure mentioned above.

\subsection{Thermal Conductivity Analysis}

The thermal conductivity of each sample was measured throughout their treatment cycles using a single thermal probe. The TLS-100 controller used comprises a $100 \mathrm{~mm}$ needle probe and was designed to comply with ASTM D5334-14 (2014) [22]. The sensor needle consists of a thin heating wire and a temperature sensor sealed in a steel tube. To measure the soil thermal conductivity, the sensor should be completely inserted into the sample to be tested. Then, heat is delivered to the sample using a constant current source, and the temperature rise is recorded over a defined period. In the current study, the thermal conductivity was measured by inserting the probe vertically through the centre of the sample and was left for 15-20 min for the sensor temperature to equalise with the sample temperature. The measurement of thermal conductivity was then recorded, and this was repeated each day after a new treatment cycle. 
According to the line heat source theory, the calculation of thermal conductivity of soil is dependent on the heating power $(q)$ and slope for the rise in temperature over the logarithm of time. The thermal conductivity can thus be calculated using the following equation [9]:

$$
k=\frac{q}{4 \pi a}=\frac{r I^{2} \ln (t)}{4 \pi \Delta T}
$$

where: $k=$ thermal conductivity in $\mathrm{W} / \mathrm{mK} ; q=$ heating power in $\mathrm{W} / \mathrm{m} ; a=$ slope for the rise in temperature over the logarithm of time; $\Delta T=$ temperature rise; $t=$ time since the application of heat in seconds; $r=$ the resistance per meter of the heating element; and $I$ = current.

\subsection{Microstructure Analysis}

Scanning electron microscopy (SEM) is a direct method of explaining the interaction and morphology of bio-cemented samples at the microscopic level. This analysis was included in this study to examine the morphology of the precipitated $\mathrm{CaCO}_{3}$ and $\mathrm{MgCO}_{3}$ crystals and the formation of the thermal bridges. The SEM study was conducted on the samples containing $100 \% \mathrm{CaCl}_{2}$ and $100 \% \mathrm{MgCl}_{2}$ after three treatment cycles. The samples containing $1.5 \%$ steel and glass fibres were also examined. Before the SEM analysis, $1-2 \mathrm{~cm}$ cube from each sample was retrieved and dusted to remove any loose particles.

\section{Results and Discussions}

\subsection{Analysis of Thermal Conductivity for MICP-Treated Soil}

A total of 14 specimens were tested to determine the optimum cementation solution constituents for improving the thermal conductivity of the sand used. The pores between the soil particles for each sample were filled with water to improve the thermal conductivity since water has a higher thermal conductivity value, $k$, of $0.595 \mathrm{~W} / \mathrm{mK}$ compared to the $k$ value of air $(0.026 \mathrm{~W} / \mathrm{mK})$. The thermal conductivity of an untreated, fully saturated sand sample was measured to be $1.728 \mathrm{~W} / \mathrm{mK}$. Figure 3 displays the results of the thermal conductivity tests after one treatment cycle, which indicates that each of the different concentrations of cementation solution was able to improve the soil thermal conductivity. However, the thermal conductivity was optimised using $100 \%$ in the cementation solution. The production of calcite within the soil pores improved the thermal conductivity as it formed thermal bridges. However, the improvement in thermal conductivity using the MICP process was reduced with the increase in $\mathrm{MgCl}_{2}$ concentration in the cementation solution. It was found that the thermal conductivity of $\mathrm{MgCl}_{2}$ precipitates was lower than that of the $\mathrm{CaCl}_{2}$, which is in agreement with previous work which reported that the thermal conductivity of $\mathrm{MgCl}_{2}$ precipitates is five times lower than that of the $\mathrm{CaCl}_{2}$ precipitates [23].

Figure 4 displays the relationship between the thermal conductivity and different treatment cycles. In general, it was found that each of the treated samples containing different cementation solutions improved in thermal conductivity as the number of treatment cycles was increased. The samples treated with a higher content of $\mathrm{CaCl}_{2}$ resulted in a larger increase in thermal conductivity for each treatment cycle (an increase of $0.546 \mathrm{~W} / \mathrm{mK}$ from the first treatment cycle to the third) when compared to the other samples. The increased thermal conductivity was attributed to the increased dry density of soil due to the precipitation of $\mathrm{CaCO}_{3}$ following the MICP treatment. It has also been demonstrated previously that an increase in thermal conductivity with an increase in dry density is due to the repeated treatment of MICP [9]. 


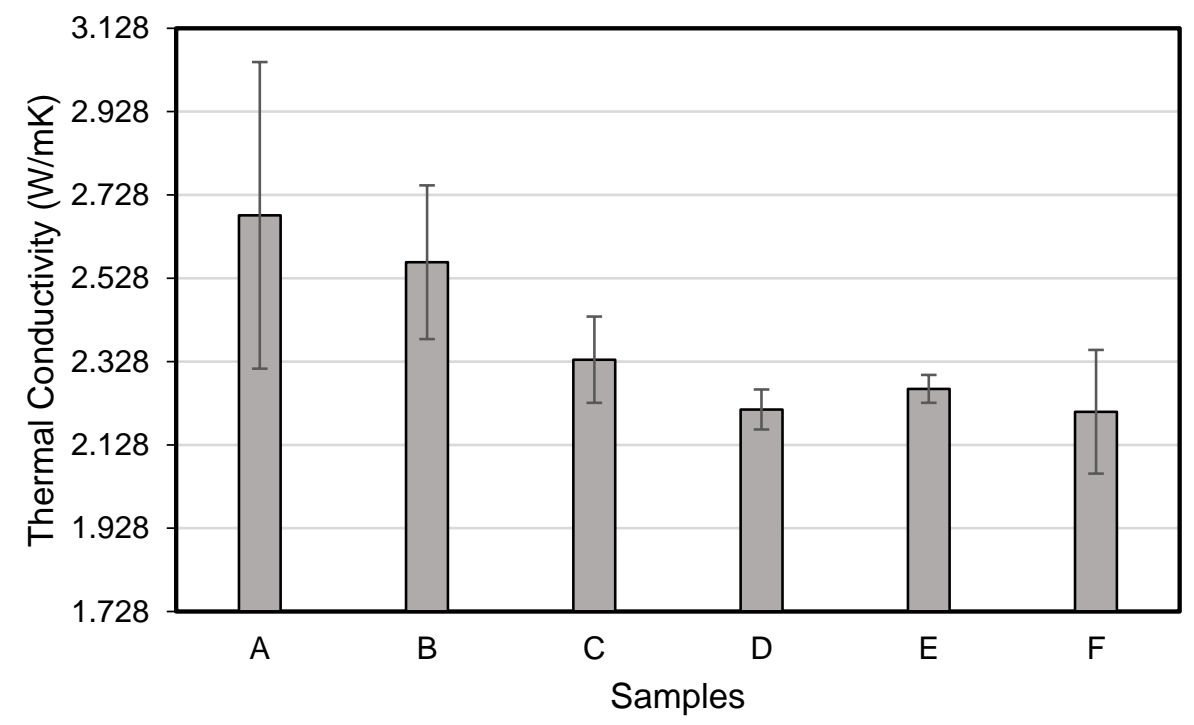

Figure 3. Thermal conductivity of MICP-treated sand using different cementation solutions (untreated soil had thermal conductivity $=1.728 \mathrm{~W} / \mathrm{mK}$ ).

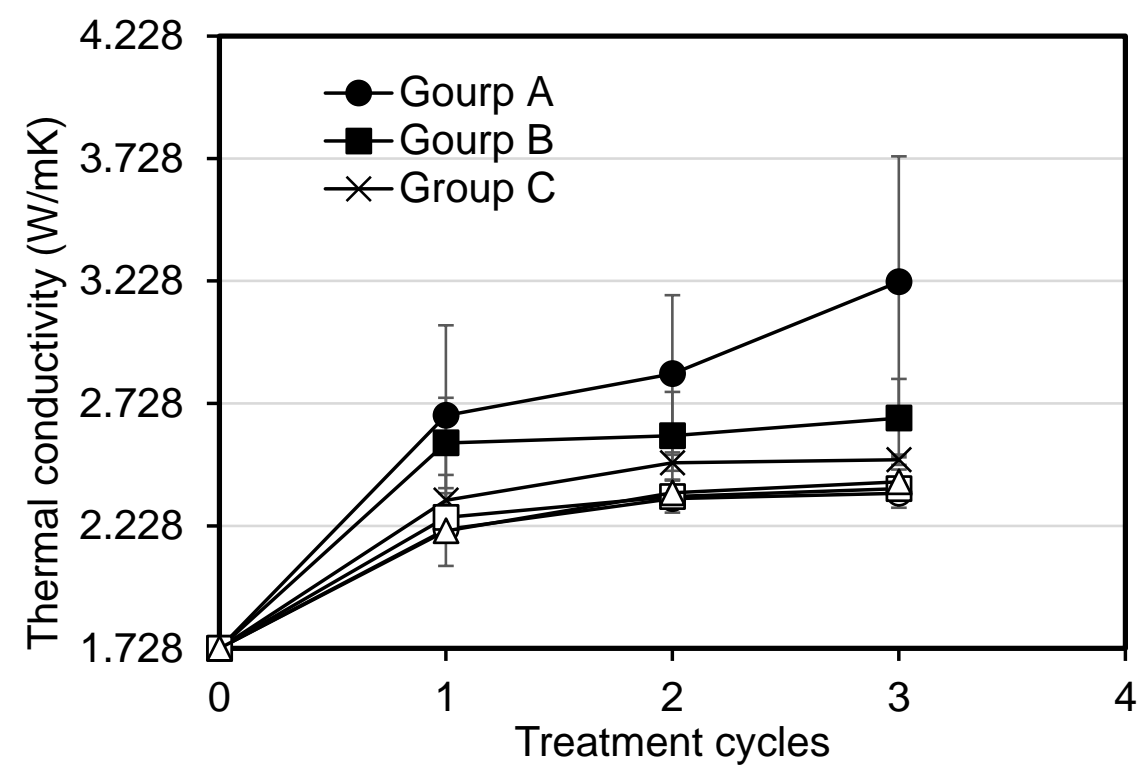

Figure 4. Thermal conductivity of sand samples after multiple treatments with different cementation solutions.

It was proposed to use magnesium chloride as a substitute for calcium chloride as it is not only less expensive but could also bring extra benefits such as further strength improvement. Despite this, a larger number of treatment cycles using high concentrations of $\mathrm{MgCl}_{2}$ would be required to achieve a similar thermal conductivity to the samples with higher $\mathrm{CaCl}_{2}$ content. The field application of MICP usually requires a large amount of land to be treated, meaning that multiple treatment cycles may not ultimately be a cost-effective option when using a high content of $\mathrm{MgCl}_{2}$.

A fraction of the bio-treated samples with $100 \% \mathrm{CaCl}_{2}$ and $100 \% \mathrm{MgCl}_{2}$ were examined by SEM. It can be seen from Figure $5 \mathrm{a}, \mathrm{b}$ that the favourable conditions of using $100 \% \mathrm{CaCl}_{2}$ resulted in a collection of clusters of calcium carbonate crystals that connected most of the sand grains. It can also be seen in Figure $5 \mathrm{~b}$ that the calcite bridges connecting the sand particles are rather large and provide a large contact area. This area of contact amongst the grains provides a larger path for energy to be transferred within the soil matrix, hence improving the soil thermal conductivity. In Figure $5 b$, it can be seen that the sand grain is 
almost completely covered with the calcite crystals and bonded to the adjacent particles by almost its complete length. Before treatment, the soil particles would likely have had a single point of contact. The calcite induced by the MICP treatment filled the pore space between the soil particles, thus providing thermal bridges to allow for a more efficient path for heat transfer. The thermal conductivity of $\mathrm{CaCO}_{3}$ is greater than that of water and air; thus, filling the pores with thermal bridges would significantly improve the soil thermal conductivity.
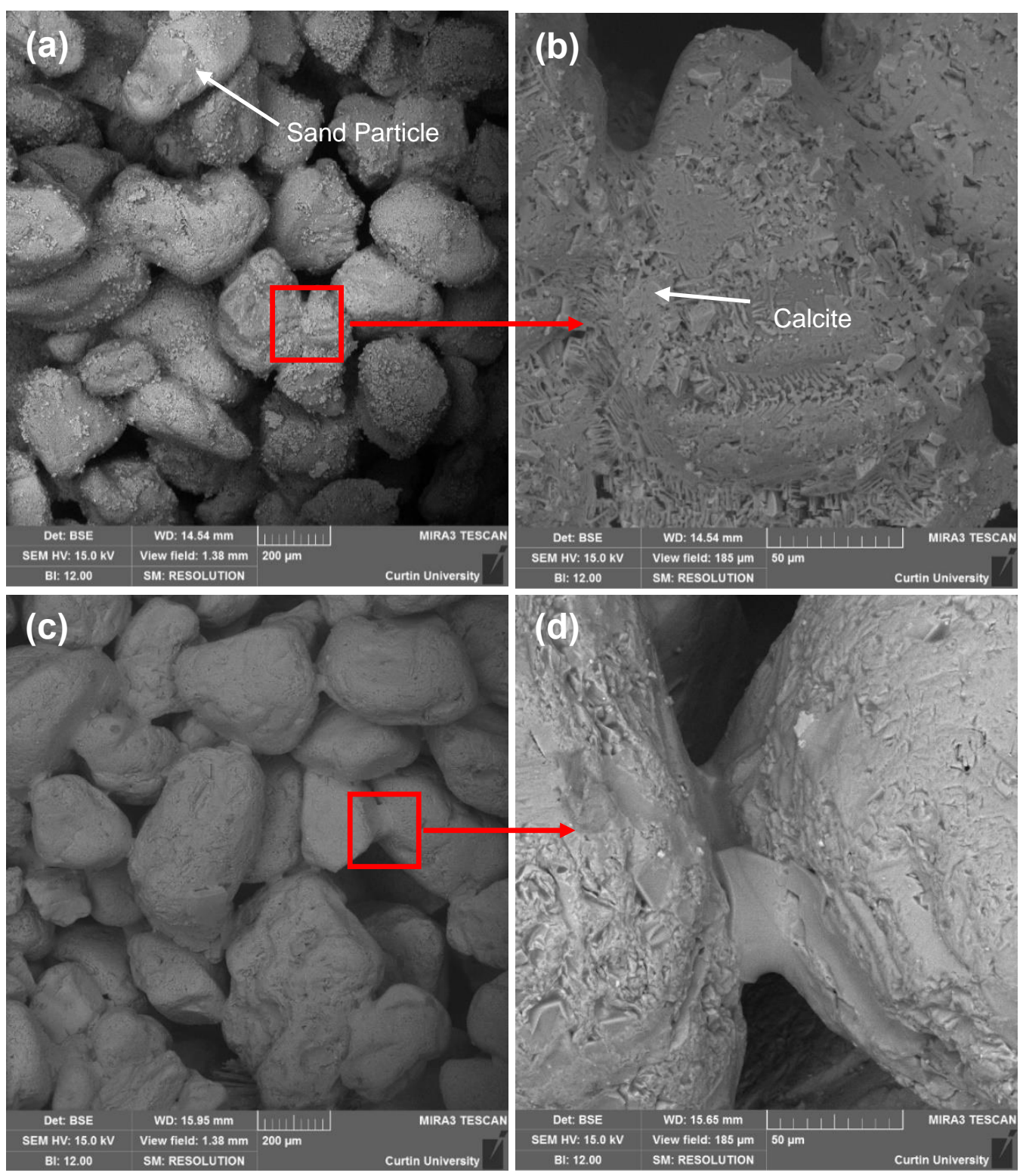

Figure 5. SEM imaging showing microstructure of the soil sample treated with $100 \% \mathrm{CaCl}_{2}(\mathbf{a}, \mathbf{b})$ and $100 \% \mathrm{MgCl}_{2}$ (c,d).

Figure 5c,d shows SEM imaging of the less favourable conditions of using $100 \% \mathrm{MgCl}_{2}$. The results show no obvious formation of the magnesium carbonate crystals, and the sand particles exhibited a much smoother surface texture when compared to those of the $100 \%$ $\mathrm{CaCl}_{2}$. It should be mentioned that the morphology of the crystals precipitated from the $100 \% \mathrm{MgCl}_{2}$ solution differs from the $100 \% \mathrm{CaCl}_{2}$. The higher $\mathrm{CaCl}_{2}$ resulted in crystals with a rhombohedral form, whereas the higher $\mathrm{MgCl}_{2}$ resulted in irregular crystals. The smooth bridging between the sand grains can be observed in Figure $5 d$, which shows that the contact area is not as high as the desired sample. There is also more gapping present 
in the soil matrix, signifying that the contact area is not relatively large. For energy to be transferred more efficiently between the surrounding soil of energy piles, the gapping between the soil particles must be minimised. Consequently, the increased amount of gapping and relatively small crystal bridging has resulted in a smaller improvement in thermal conductivity in the sample containing $100 \% \mathrm{MgCl}_{2}$.

\subsection{Analysis of Thermal Conductivity for Fibre-MICP-Treated Soil}

Three different types of fibres were used in this study to determine how the thermal conductivity would be affected by their different properties. The fibres used include polyethylene, steel and glass. The thermal conductivities of such fibres were determined from the literature to be $0.33 \mathrm{~W} / \mathrm{mK}, 50.2 \mathrm{~W} / \mathrm{mK}$ and $0.043 \mathrm{~W} / \mathrm{mK}$, respectively. Thus, it was expected that the samples containing steel fibres would result in higher thermal conductivity. Each sample was treated in the same manner, with $100 \% \mathrm{CaCl}_{2}$ in the cementation solution.

Figure 6a shows that the MICP-treated soil samples containing steel yielded the highest thermal conductivity after the 1st cycle of treatment compared to other samples, which is due to the high thermal conductivity of steel fibres. In contrast, the thermal conductivity results for the polyethylene fibres showed the lowest improvement in thermal conductivity. This is because the thermal conductivity of polyethylene fibres is lower than that of calcium carbonate and sand; thus, it is expected that a larger quantity of fibres would reduce the thermal conductivity of the sand-fibre mixture.

Figure 6 shows that the thermal conductivity increases after each treatment cycle for the polyethylene and glass fibres as the calcite precipitation forms thermal bridges between the fibres and soil particles after each subsequent treatment cycle. For example, Figure $6 \mathrm{c}$ shows that after the third treatment cycle, the soil samples containing $0.5 \%, 1.0 \%$ and $1.5 \%$ of glass fibres can improve the thermal conductivity of the fibre-soil mixture by $168 \%, 166 \%$ and $151 \%$, respectively. However, this is not the case for steel fibre. As shown in Figure 6, a reduction in the thermal conductivity with treatment for the samples containing $1.0 \%$ and $1.5 \%$ of steel fibre was obtained. This reduction is probably attributed to the corrosive nature of steel fibre, which occurs as a result of the moisture of the sample, chloride ions from the cementation solution and the alkali conditions of the MICP treatment reactions. Here, ferrous ions $\left(\mathrm{Fe}^{+}\right)$detach from the steel and react with oxygen molecules $\left(\mathrm{O}_{2}\right)$ and hydroxide ions $\left(\mathrm{OH}^{-}\right)$to produce a by-product of the corrosion reaction, rust. This by-product was observed as an orange-brown discolouration surrounding the steel fibres, as shown in Figure 6c. The thermal conductivity of iron oxide (rust) is found to be $0.58 \mathrm{~W} / \mathrm{mK}$, which is less than the water and calcite [24]. As a result, the samples containing a larger amount of steel fibres resulted in high corrosion, which subsequently reduced their thermal conductivity after each treatment cycle.

A fraction of the bio-treated samples containing steel and glass fibres were examined by SEM as these samples presented opposite thermal conductivity trends as indicated above. The microstructures for the samples containing 1.5\% steel and glass fibres are shown in Figure 7, which demonstrates a clear bonding between the fibres and bio-cemented sand particles in all cases. Figure $7 \mathrm{a}, \mathrm{b}$ shows a good distribution of the steel fibres within the soil matrix and appears to be well embedded between the particles. The chemical composition of coating on the steel fibre surface was explored using energy-dispersive $X$-ray spectroscopy (EDS), and it was confirmed that the steel fibre was covered by iron oxide after repeated MICP treatments. This further supports the findings of thermal conductivity being affected by the corrosive nature of steel fibre. Figure 7c,d displays the SEM images for the bio-cemented samples containing glass fibre. As observed by the SEM images, the fibre is secured by large thermal bridges, providing a more efficient pathway for energy transfer. 

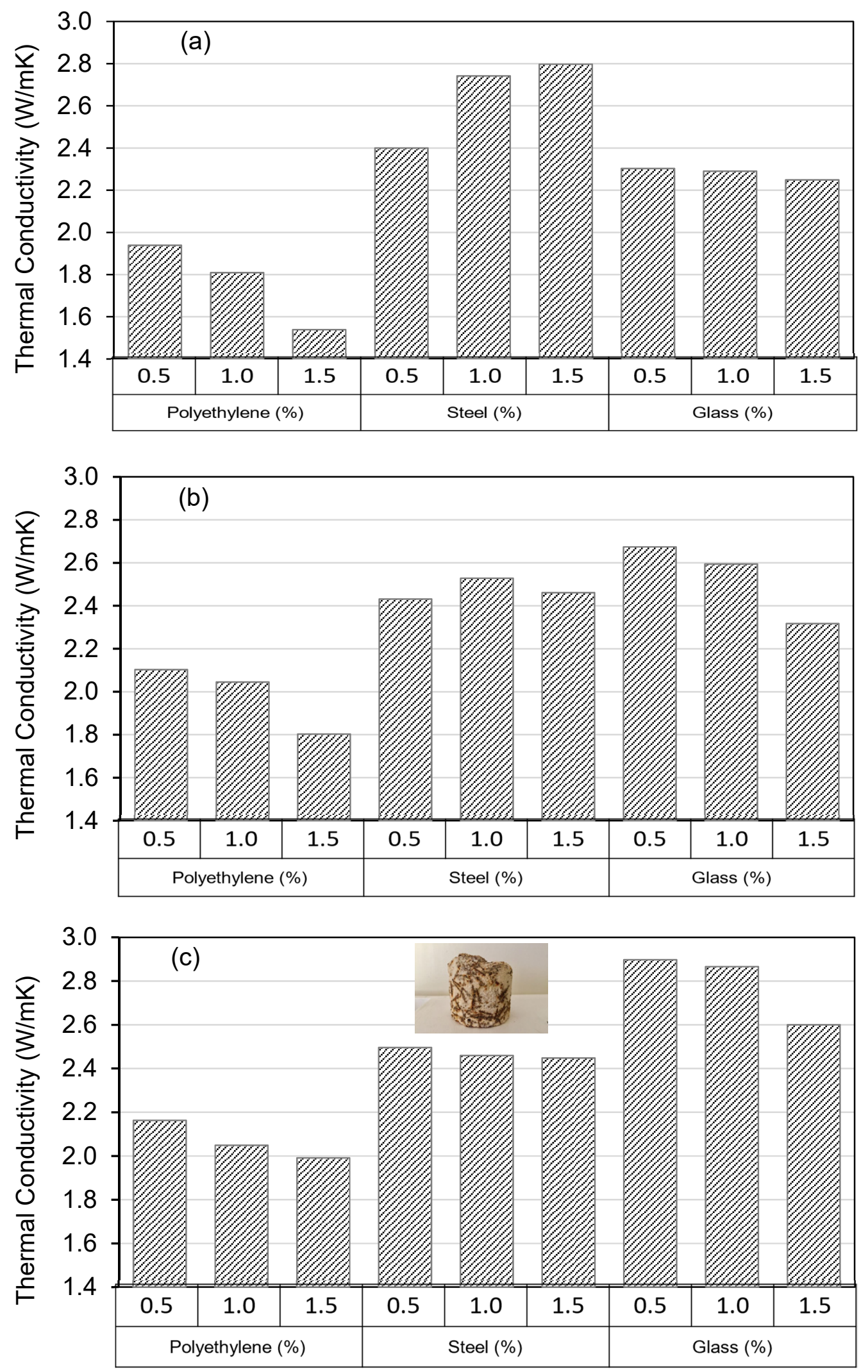

Figure 6. Thermal conductivity of fibre-sand mixture after MICP treatment: (a) 1st treatment; (b) 2nd treatment; and (c) 3rd treatment. 

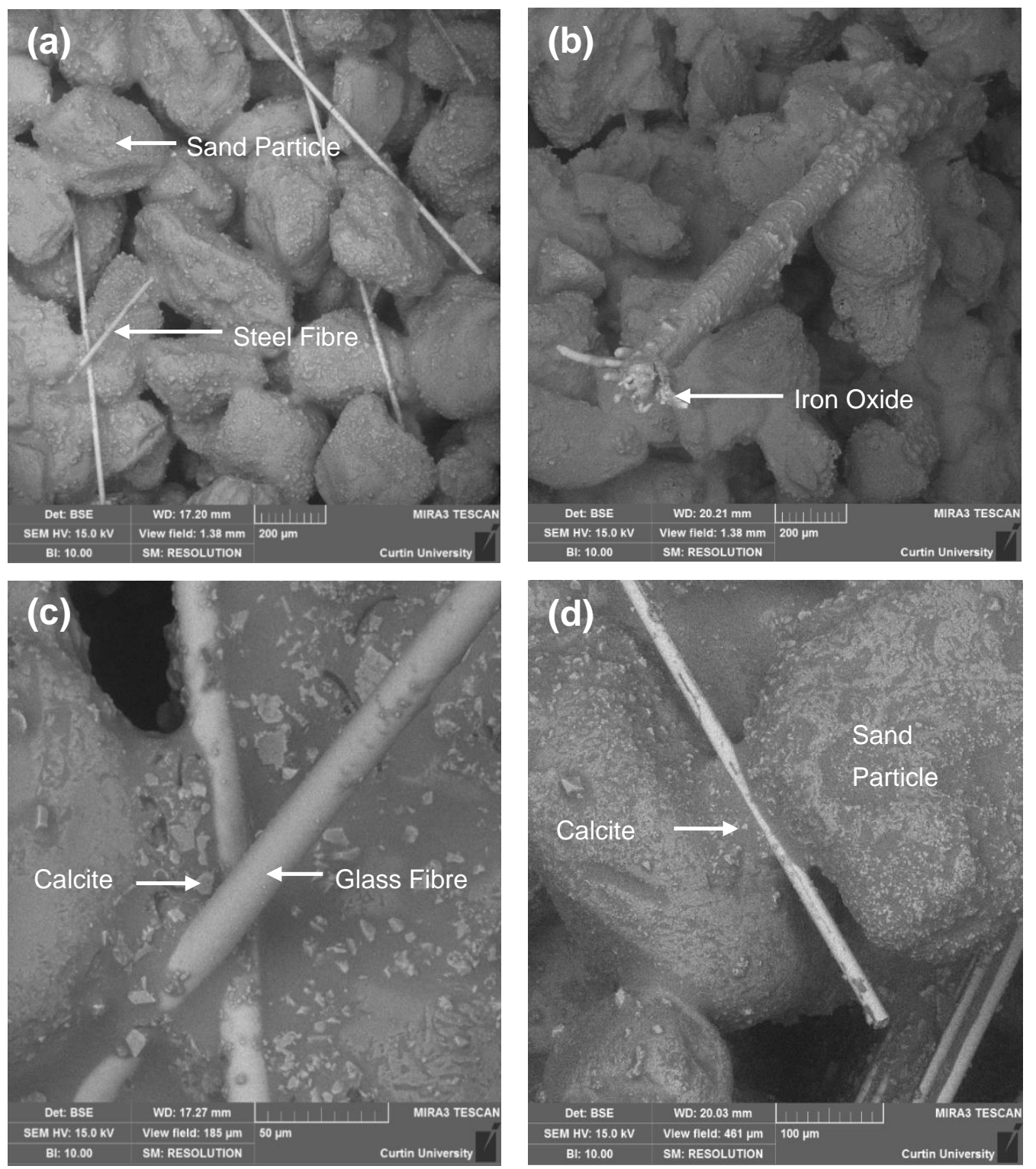

Figure 7. SEM imaging showing the microstructure of soil specimens containing $1.5 \%$ steel fibre $(\mathbf{a}, \mathbf{b})$ and glass fibre $(\mathbf{c}, \mathbf{d})$.

\section{Conclusions}

In this study, the thermal conductivity of bio-cemented sand was measured using different cementation solutions, with and without the addition of fibres. It was determined that using $100 \%$ calcium chloride resulted in the highest thermal conductivity of $3.225 \mathrm{~W} / \mathrm{mK}$, thus improving the thermal conductivity of bio-cemented sand by $187 \%$. All samples improved the thermal conductivity of sand, although those containing higher $\mathrm{CaCl}_{2}$ contents were more effective. Upon conducting SEM analyses, it was evident that the samples containing $100 \%$ calcium chloride created larger crystals and, in turn, thermal bridges between the soil particles compared to the samples containing $100 \%$ magnesium chloride. The formation of such extensive thermal bridges resulted in a higher transfer of heat energy between soil particles, which was further developed after each treatment cycle for all samples.

The results of the samples containing different fibres show that the steel fibres yielded the highest thermal conductivities after one treatment cycle. However, the samples containing polyethylene and glass fibres resulted in lower thermal conductivity due to the low thermal conductivity of the fibres themselves. Upon further treatment cycles, the 
samples containing $1.0 \%$ and $1.5 \%$ of steel fibres reduced in thermal conductivity. This was attributed to the corrosive nature of the fibres producing low-thermal-conductivity iron oxide and disassembling the calcite bonds, which further reduced the effectiveness of the sand sample to transfer heat energy efficiently.

This research suggests that using MICP as a soil improvement technique can also improve the thermal conductivity of soil surrounding energy piles, which has high potential to effectively improve the efficiency of energy piles. This study also suggests that using the traditional MICP cementation solution containing calcium chloride provides the most effective results regarding heat transfer. With further investigation into the factors influencing the field applications, the MICP technique could be an effective way of improving the efficiency of energy piles for a more sustainable solution to the heating and cooling of buildings.

Author Contributions: Conceptualization, L.C. and M.A.S.; Methodology, L.C. and M.A.S.; Validation, L.C. and N.A.; Formal Analysis, L.C. and N.A.; Investigation, N.A. and M.A.S.; Data Curation, N.A.; Writing-Original Draft Preparation, N.A.; Writing-Review and Editing, L.C. and M.A.S.; Supervision, M.A.S.; Project Administration, M.A.S. All authors have read and agreed to the published version of the manuscript.

Funding: The authors would like to thank the financial support from Curtin University through the Undergraduate Final Year Project scheme. The authors would also like to thank the financial support from Jiangsu Provincial Department of Education through the Jiangsu Distinguished Professor scheme.

Acknowledgments: The authors acknowledge the SEM experiments conducted in this research were undertaken using the EM instrumentation (ARC LE130100053) at the John de Laeter Centre of Curtin University.

Conflicts of Interest: The authors declare no conflict of interest.

\section{References}

1. Buckland, P.; Janetos, A.; Schimel, D. The Effects of Climate Change on Agriculture, Land Resources, Water Resources, and Biodiversity in the United States. In Synthesis and Assessment Product 4.3 Report by the U.S. Climate Change Science Program and the Subcommittee on Global Change Research; Department of Agriculture: Washington, DC, USA, 2008; p. 362.

2. Abuel-Naga, H.; Raouf, M.I.N.; Raouf, A.M.I.; Nasser, A.G. Energy Piles: Current State of Knowledge and Design Challenges. Environ. Geotech. 2015, 2, 195-210. [CrossRef]

3. van Paassen, L.A.; Ghose, R.; van der Linden, T.J.M.; van der Star, W.R.L.; van Loosdrecht, M.C.M. Quantifying Biomediated Ground Improvement by Ureolysis: Large-Scale Biogrout Experiment. J. Geotech. Geoenviron. Eng. 2010, 136, 1721-1728. [CrossRef]

4. Cheng, L.; Shahin, M.A.; Chu, J. Soil Biocementation using a New One-Phase Low pH Injection Method. Acta Geotech. 2019, 14, 615-626. [CrossRef]

5. Mujah, D.; Shahin, M.A.; Cheng, L.; Karrech, A. Experimental and Analytical Study on Geomechanical Behavior of Biocemented Sand. Int. J. Geomech. 2021, 21, 04021126. [CrossRef]

6. Yang, Y.; Chu, J.; Cao, B.; Liu, H.L.; Cheng, L. Biocementation of Soil using Non-Sterile Enriched Urease-Producing Bacteria from Activated Sludge. J. Clean. Prod. 2020, 262, 121315. [CrossRef]

7. Venuleo, S.; Laloui, L.; Terzis, D.; Hueckel, T.; Hassan, M. Microbially Induced Calcite Precipitation Effect on Soil Thermal Conductivity. Géotech. Lett. 2016, 6, 39-44. [CrossRef]

8. Wang, Z.Y.; Zhang, N.; Ding, J.H.; Li, Q.; Xu, J.H. Thermal Conductivity of Sands Treated with Microbially Induced Calcite Precipitation (MICP) and Model Prediction. Int. J. Heat Mass Transf. 2020, 147, 118899. [CrossRef]

9. Wang, Z.Y.; Zhang, N.; Lin, F.; Ding, J.H.; Yang, H.M. Thermal Conductivity of Dry Sands Treated with Microbial-Induced Calcium Carbonate Precipitation. Adv. Mater. Sci. Eng. 2019, 2019, 1-8. [CrossRef]

10. Xu, X.; Guo, H.; Cheng, X.; Li, M. The Promotion of Magnesium Ions on Aragonite Precipitation in MICP Process. Constr. Build. Mater. 2020, 263, 120057. [CrossRef]

11. Putra, H.; Yasuhara, H.; Kinoshita, N.; Neupane, D.; Lu, C.-W. Effect of Magnesium as Substitute Material in Enzyme-Mediated Calcite Precipitation for Soil-Improvement Technique. Front. Bioeng. Biotechnol. 2016, 4, 37. [CrossRef] [PubMed]

12. Choi, S.-G.; Wang, K.J.; Chu, J. Properties of Biocemented, Fiber Reinforced Sand. Constr. Build Mater. 2016, 120, 623-629. [CrossRef]

13. Choi, S.-G.; Hoang, T.; Alleman, E.J.; Chu, J. Splitting Tensile Strength of Fiber-Reinforced and Biocemented Sand. J. Mater. Civ. Eng. 2019, 31, 06019007. [CrossRef] 
14. Sahlabadi, S.H.; Bayat, M.; Mousivand, M.; Saadat, M. Freeze-Thaw Durability of Cement-Stabilized Soil Reinforced with Polypropylene/Basalt Fibers. J. Mater. Civ. Eng. 2021, 33, 04021232. [CrossRef]

15. Zhao, Q.; Li, L.; Li, C.; Li, M.D.; Amini, F.; Zhang, H.Z. Factors Affecting Improvement of Engineering Properties of MICP-Treated Soil Catalyzed by Bacteria and Urease. J. Mater. Civ. Eng. 2014, 26, 04014094. [CrossRef]

16. Australian Standards. Method of testing soils for engineering purposes. In Australian Standard AS 1289; Australian Standards: Strathfield, NSW, Australia, 2007.

17. Cheng, L.; Cord-Ruwisch, R.; Shahin, M.A. Cementation of Sand Soil by Microbially Induced Calcite Precipitation at Various Degrees of Saturation. Can. Geotech. J. 2013, 50, 81-90. [CrossRef]

18. Mujah, D.; Cheng, L.; Shahin, M.A. Microstructural and Geomechanical Study on Biocemented Sand for Optimization of Micp Process. J. Mater. Civ. Eng. 2019, 31, 04019025. [CrossRef]

19. AS/NZS 1477:2017, PVC Pipes and Fittings for Pressure Applications; Standards Australia: Strathfield, NSW, Australia, 2017.

20. Cheng, L.; Shahin, M.A.; DMujah, D. Influence of Key Environmental Conditions on Microbially Induced Cementation for Soil Stabilization. J. Geotech. Geoenviron. Eng. 2017, 143, 04016083. [CrossRef]

21. Whiffin, V.S.; Van Paassen, L.A.; Harkes, M.P. Microbial Carbonate Precipitation as a Soil Improvement Technique. Geomicrobiol. J. 2007, 24, 417-423. [CrossRef]

22. ASTM D5334-14, Standard Test Method for Determination of Thermal Conductivity of Soil and Soft Rock by Thermal Needle Probe Procedure; ASTM International: West Conshohocken, PA, USA, 2014.

23. Awad, M.M. Fouling of Heat Transfer Surfaces. In Heat Transfer-Theoretical Analysis, Experimental Investigations, and Industrial System; Belmiloudi, A., Ed.; IntechOpen: Rijeka, Croatia, 2011.

24. Engineering Toolbox. Thermal Conductivity of Selected Materials and Gases; The Engineering ToolBox; 2003. Available online: www.EngineeringToolBox.com (accessed on 2 August 2021). 